\title{
Innovative Exploration of Capital Science and Technology Resource Platform: Theory and Case Study
}

\author{
Fugang Zhao, Quwen Deng \\ Guangdong Science and Technology Library, Guangzhou, China \\ Email: 275475938@qq.com
}

Received 11 March 2016; accepted 14 May 2016; published 18 May 2016

Copyright (C) 2016 by authors and Scientific Research Publishing Inc.

This work is licensed under the Creative Commons Attribution International License (CC BY).

http://creativecommons.org/licenses/by/4.0/

(c) (7) Open Access

\begin{abstract}
To promote sharing of science and technology resource in universities and research institutes, Beijing Municipal Science and Technology Commission started a reform of the Capital Science and Technology Resource Platform (CSTRP) in 2009. Due to great success, CSTRP's new practice is under consideration to be introduced to other provinces in China. This paper introduces the characteristics and highlights of CSTRP, discusses the underlying theories including triple helix theory, multi-level governance theory and innovation network theory, and makes a case study in detail. Finally, suggestions on CSTRP's future development are discussed.
\end{abstract}

\section{Keywords}

Share of S \& T Resource, Triple Helix, Multi-Level Governance, Innovation Network

\section{Introduction}

\subsection{S \& T Resource Distribution in Beijing}

Beijing, as the politic center, the economic center as well as the technology center of China, occupies about onethird of the whole nation's science and technology (S \& T) infrastructure resources, including State Key Laboratories, National Engineering Technology Research Centers, National Engineering Research Centers, National Engineering Laboratories and National Enterprise Technology Centers, leading up to Beijing's key role in the development of our national technology system.

It is noticed that the distribution of the $\mathrm{S} \& \mathrm{~T}$ resources in Beijing presents a clear agglomeration effect, with universities and large research institutes being the key owners. Universities and research institutes got nearly $80 \%$ of the total S \& T investment made by central government and local government in Beijing. According to a sur- 
vey conducted by Beijing Municipal Science and Technology Commission, among the 6709 sets of equipment (each of which was worth more than 100 thousand RMB), nearly $80 \%$ were owned by research institutes and universities. However, large resource owners, i.e., research institutes and universities didn't have good innovation output performance compared with enterprises in general. In 2014, enterprises in Beijing made only 36.5\% of total internal R \& D expenditures in society but accounted for 68.8\% of patent applications and $69.9 \%$ of patents granted in total [1]; among technology sellers in Beijing technology market in 2014, research institutes and universities respectively generated only $2.7 \%$ and $0.7 \%$ of total technology transfer turnover while enterprises accounting for 96.4\% [2]. Meanwhile, enterprises, especially SMEs, have strong need for these S \& T resources but could hardly reach them.

Such an unbalanced S \& T resource investment leads the sustainable technology and economy development to big challenges. On one hand, universities and large research institutes who have all these considerable resources, both in quantity and quality, are far from optimizing their usage to the benefit of the whole society: problems of unnecessary duplication largely exists. On the other hand, although many SMEs have quite strong motivations to innovate, they are still facing bottlenecks in achieving necessary resources in the hand of universities and large research institutes. Apparently, enhancing the usage and the sharing of the available technological resources will be beneficial to both parties and achieve a direct cut of innovation cost on both regional and national levels.

\subsection{The System Reformation of CSTRP}

Beijing Science and Technology Committee started the construction of the Capital Science and Technology Resource Platform (CSTRP) in 2003 to promote the sharing of the valuable S \& T resources. However, large quantity of S \& T resources owned by universities and research institutes were not opened to the SMEs by 2008. When digging deeper into the reasons, Beijing Science and Technology Committee finds the key problems in the mechanism: generally speaking, there are few requirements and motivations for the owner to share the resources due to the existing S \& T management system. University institutions generally lack professional institutions and personnel to market their S \& T resources. In order to overcome these barriers, Beijing Science and Technology Committee implemented the reformation of the Capital Science and Technology Resource Platform (CSTRP) in 2009. Professional operating agencies are introduced as the third party to market the S \& T resources in universities and research institutes. Under the operational guidance from the government, a win-win mechanism among S \& T resource owners, marketing operators and other related actors is created without dramatically changing the existing institutional framework or disturbing the profound interest of any actors.

Up till late 2014, the CSTRP has been proved successful: Since 2009, equipments valued at 19.2 billion yuan scattered in more than 676 national and/or municipal key laboratories and engineering center were open to society, more than 10000 SMEs enjoyed the services through CSTRP in year 2014, and a total contract value of 2.1 billion RMB had been reached. Using the multi-level governance method, CSTRP closely and organically integrates different actors involved in technological innovations process, i.e., the universities as suppliers, the SMEs as users, the professional operating agencies as intermediaries and the government as coordinator and supporters. Within CSTRP, the roles of government, industry and university complement each other and intertwine to form an organic triple helix model, forming strong ties in innovation network, serving better than the previous cooperation method in matching the demand and supply of technological innovation and have been creating a considerable economic value. CSTRP's new practice is well known as Beijing mode to promote openness and sharing of S \& T Resource and attracts many other provinces in China to learn from its experience.

\section{Related Theories}

\subsection{Triple Helix Theory}

In 1953, Linus Pauling and Robert B. Corey raised the assumption that DNA is composed by three strands, forming a shape of a spiral string. A few months later, Francis Crick and James Watson were honored the Noble Prize for discovering what is accepted to be the correct structure of DNA, the double helix formation. A double helix could maintain stable stage, and by comparison, a triple helix could have various and chaotic behaviors. Therefore, triple helix began to be used for analyzing complicated transformation process, such as the innovation process. 
Henry Etzkowitz and Loet Leydesdorff introduced the triple helix model to analysis the relationship and interaction among university, industry and government in innovation process. Different from the linear innovation model that simply equals innovation to the application of scientific theories and the National System of Innovation model that regards firms as the core of the innovation system, the triple helix theory states that regional or industrial innovation relies on the trilateral interaction among university, industry and government: none of the three parties occupies the leading role, they're all organizers and participants of the innovation activities, they interact with each other, rely on each other and pushing further the innovation process together [3].

According to Etzkowitz and Leydesdorff, a minimum of three forms of triple helix model were identified: Triple helix I, in which the government determines the relation between university and industry, is generally considered to be a failed development model. In Triple helix II, government has diminished its control over the other parties, and each of the three institutional spheres has clear borders as well as distinctive relations among them. Triple helix III, in which overlapping institutional spheres form a knowledge infrastructure and each party taking the role of the other, generates trilateral networks and hybrid organizations [3].

The third form of triple helix model, which is shown in Figure 1, is becoming widely accepted and pursued by many nations. Although the triple helix model distinguishes its three components: university, industry and government, it also emphasizes that their borders are fading out and all three parties, besides fulfilling their own functions, are undertaking certain roles of the other parties, and as a result many hybrid organizations emerge at the interfaces, such as derivate firms set-up by university students and government-led industry innovation unions.

According to triple helix theory, synchronicity and compatibility among the three helices is important: if one or two helices couldn't match with each other, the synergy of innovation could not be achieved. Therefore, only by virtuous interaction among university, industry and government in the process of generating, spreading and applying new knowledge can the whole network be effectively improved. Besides, to overcome "market failure", it is important for the government to actively promote cooperation between different actors [4].

\subsection{Multi-Level Governance Theory}

The concept of multi-level governance was developed by Gary Marks in comparison to state-centric governance when evaluating the European integration and the European Union (EU) performance. The EU System includes three levels, i.e., Europe level, national level and regional level. In order to generate an effective force inside EU, a joint-action mechanism has to be formed within as well as between different levels. Open method of coordination (OMC) is a multi-level governance method developed in this background. OMC doesn't rely solely on executive power, instead it is a coordination mechanism based on guidelines, benchmarks and experience sharing. The basic operational procedure is implemented as follows: firstly, an objective, which is usually rather broad, is raised by the EU level; secondly, the EU member countries bring out national or regional policies according to

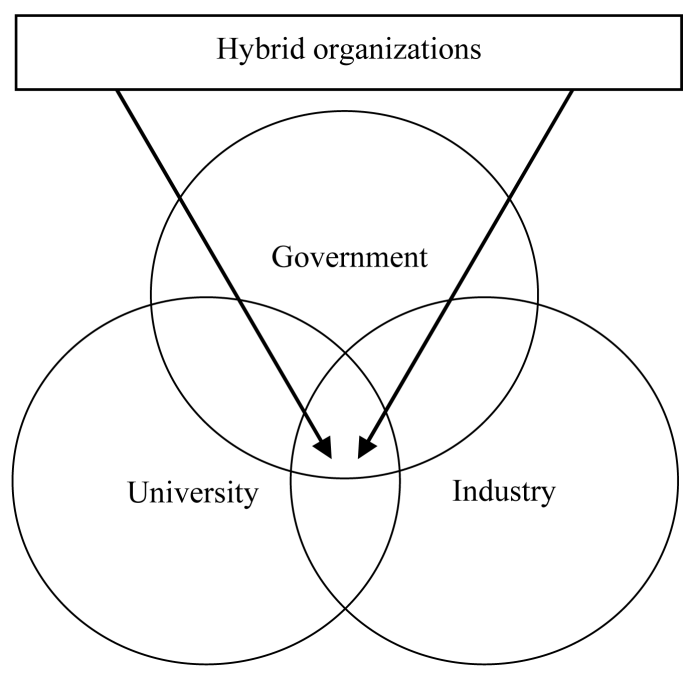

Figure 1. Triple helix III. 
the guidelines; thirdly, benchmarks are selected among all the countries, and meanwhile, evaluation indicators are formed; finally, practice carried out in each countries are monitored and evaluated accordingly. OMC was first applied to the EU employment policy, and later carried out to the field of pension fund, health care, immigration, and education etc [5] [6].

Robert Kaiser and Heiko Prange pointed out that for OMC to be better applied to innovation policies, two factors must be considered: multi-level character of innovation policies and high diversity of national innovation systems [7]. The process of making National innovation policy should fully involve related actors. The multilevel governance method is of great reference to CSTRP since its construction involves a minimum of three different levels, along with joint-actions within and between different levels:

\section{1) R \& D Service Base}

Each is jointly constructed by a resource owner (university and research institute) and a professional operating agency to supply technological innovation service together. It is an alliance due to cooperation agreement rather than a legal entity. This paper mainly interprets the practice of R \& D service base since it is organizational and institutional innovative.

\section{2) Field Center}

Each is operated by a specialized centers affiliated to Beijing Science and Technology Committee to mainly collect demand of technological service in certain industry or technical field as well as to promote resource sharing of innovators in that field. Since these specialized centers engage in publishing and managing government R \& D project or initiating and organizing industry alliances, they have relationships with many innovators that own $S$ \& T resources or need S \& T resources.

\section{3) Working Station}

It is jointly constructed by Beijing Science and Technology Committee and district government inside Beijing and regional governments outside Beijing to collect service demand.

By the end of 2014, 27 R \& D research bases, 12 field centers and 14 working stations are contained in CSTRP system.

\subsection{Innovation Network Theory}

Innovation network is institutional arrangement for systematic innovation. The structure of network is the cooperative relationship among actors in innovation process. Freeman interpreted the types of innovation network, including joint research company, cooperative R \& D agreement, technology exchange agreement, licensing agreement, joint research sponsored by the government, etc. [8].

Innovation network includes different nodes as well as the formal and informal interactions among them. Each and every participants of the innovation process is a node of the network. Formal and fixed relations between two nodes are strong ties, and informal or implicit relations are weak ties [9]. Strong ties are more effective in complicated knowledge exchanges while weak ties have further extensions and help to exchange information with heterogeneity. Both weak and strong ties make it possible for the network to generate innovative performance exceeding the individual abilities. The utilization of external networks may act as a primary driver for innovation for those firms that are either not inclined and/or do not have the capabilities to adopt entrepreneurial culture [10].

"Structural holes" is an important concept related to innovation network. When there is no direct contact or relationship between certain nodes in the innovation network, it looks like some holes appear in the network. If third parties can create such a connection for certain nodes to have trading opportunity, they will have information superiority and create value in the innovation network.

CSTRP is essentially an innovation network based on institutional arrangement for the purpose of stimulating sharing of S \& T resources and supporting the technological innovations of the SMEs. By means of signing formal agreements and issuing administrative instructions, it establishes kinds of strong ties among Beijing Science and Technology Committee, universities and research institutes, operating agencies, SMEs and other actors, breaking the isolation and sector privatization of $S \& \mathrm{~T}$ resources.

\section{Capital Science and Technology Resource Platform}

As one of the most innovative practices in China providing S \& T resources to SMEs, Capital Science and Technology Resource Platform after the reform is highlighted in three aspects. 


\subsection{Introduction of Market-Oriented Professional Operating Agencies}

Market-oriented professional operating agencies as the third party are introduced into CSTRP to bridge the supplier and end user of the technological resources. Each university or research institute appoints one agency that operates as a qualified firm, and grants it with the right to market the S \& T resources without shifting the ownership.

Most of these professional operating agencies already provided technological service (such as testing, technology transfer etc) to SEMs and had certain kind of business relationships with the resource owners before they joined CSTRP. Therefore, the professional operating agencies have information about both the available $\mathrm{S} \& \mathrm{~T}$ resources and the existing need from the SMEs in hand, and act as intermediaries between supply side and demand side of S \& T resources. On one hand, they can take the initiative to integrate the available resources and gain trust from the owners of the resources through effective marketing operations, and on the other hand, can deeply understand the actual need of the SMEs since they already have technological service experience. Under the guideline of Beijing Science and Technology Committee's policy, a professional operating agency and a university or research institute jointly construct a R \& D service base and share the service revenue according to the predetermined obligations and rights.

\subsection{Design of a Win-Win Mechanism}

CSTRP designed a win-win mechanism (see in Figure 2) for the benefits of different actors including the government, S \& T resource owners, intermediaries and SEMs, therefore effectively enhances the activeness of both the resource owners and intermediaries to cooperate in providing effective R \& D service to the positional users [11] [12].

According to the CSTRP operational mechanism [7], S \& T resource owners can be aware of the latest market information and find research topics through direct and indirect interaction with SEMs, can apply for government joint research projects with their customers, can share part of the service revenue with professional operating agencies. Professional operating agencies can get government subsidy, enter new business area which is complementary to their current businesses and earn promising benefit, e.g., MSAL with testing service as main business begins to participate in technology transfer from Peking University to industry. SEMs can enjoy R \& D services with guaranteed quality provided by S \& T resource owners. Through the effort of CSTRP, key R \& D projects in Beijing had been supported by $\mathrm{R} \& \mathrm{D}$ service from resource owners and R \& D cost of SMEs had

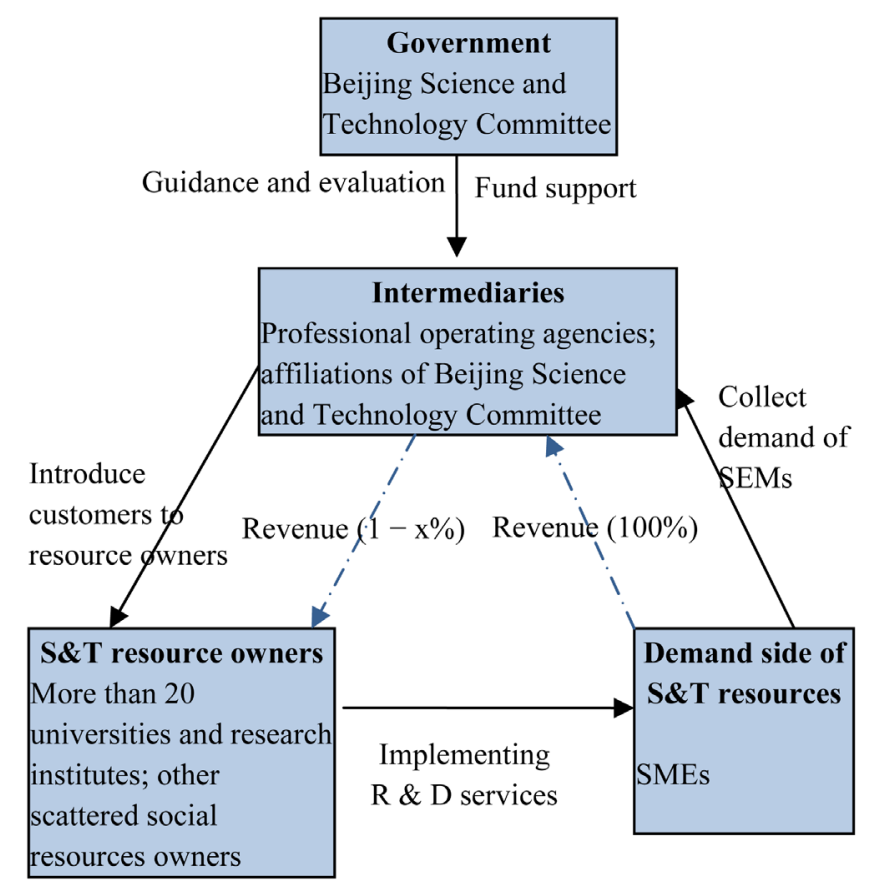

Figure 2. Operational mechanism of CSTRP. 
been significantly reduced. Problems such as unnecessary duplication and insufficient management of S \& T resources had also been resolved to a certain extent.

\subsection{Transformation in the Policy Focus}

For a long time, as most provinces in China, Beijing S \& $\mathrm{T}$ policies focused on the supply side rather than the demand side of $S \& T$ resources allocation, which leads to the mismatch of resources supply and demand. While enhancing the overall supply by encouraging universities and research institutes to open up their resources, CSTRP develops working stations to explore the demand of the SMEs. Operated by specialized centers affiliated to Beijing Science and Technology Committee (such as the Biology Center, the Software Center, the New Material Center, the Equipment Center et al.) and jointly built with other regional Science and Technology Committees, Economic Development Zone and S \& T Park, CSTRP working stations become an important channel to continuously brought the S \& T resources owners with new customers.

Beijing Science and Technology Committee tries to transform CSTRP from government funding to self-sustaining. Most other provinces in China support innovation platforms through making investment on equipment and facilities during the construction period and providing service subsidy during the operation period [13]. However, CSTRP has created a new way of using government funds. One part of 58 million RMB that Beijing Science and Technology Committee invested in 2009 were mainly used for devising feasible working mechanism that is accepted by all stakeholders including universities, research institutes, professional operating agencies, and the government. The working mechanism of CSTRP fully demonstrates the principles that those who contribute to provide services are the ones who benefit, and that those who make greater contribution are the ones who benefit more. Such principle settings ensure the cooperation between S \& T resource owners and the intermediaries and provide an institutional basis for the long-term development of CSTRP. The other part of the government fund is to subsidize the intermediaries for their marketing efforts and to enhance their ability to carry out such operations. Therefore, in CSTRP practice, government funding and self-sustaining are not two independent phases, instead, the short-term government fund is utilized for developing CSTRP's long-term selfprofit-generation ability. Furthermore, Beijing Science and Technology Committee also set up complementary policies preventing innovators who implement R \& D project funded by government of Beijing from purchasing S \& T equipments that already available in CSTRP. It not only avoids unnecessary duplication but also expands the market space of S \& T resource owners and intermediaries.

\subsection{Case Study: Peking University R \& D Service Base}

As one of the top two universities in China, Peking University owned equipments for teaching and researching totally valued at more than 1.6 billion RMB in 2009. Among them, equipments valued at 800 million RMB could be opened for providing R \& D services to SEMs. Peking University Micro Structure Analytical Laboratory (MSAL) is an independent legal entity providing testing service of X-ray diffraction (XRD) and X-ray fluorescence (XRF). In order to promote the openness of $S \&$ T resources, Peking University appointed MSAL as professional operating agency and together set up Peking University R \& D service Base in 2009. Its organizational structure is shown in Figure 3.

The leading group was formed, with the university vice-principle in charge, to make major decisions about the overall construction under the guidance of Beijing Science and Technology Committee. The administrative office was set up with 6 full-time staff and 15 part-time staff, including people from MSAL, equipment management division and different laboratories of Peking University. Deputy General Manager of MSAL is appointed director of administrative office.

In the R \& D service base, MSAL is the only authorized intermediary between resources supply and resource demand. It is fully responsible for attracting customers, coordinating laboratories scattering in different faculties to provide qualified R \& D service, as well as conducting industrial service demand surveys and getting feedbacks from SEMs periodically. The equipment management division takes charge of selecting suitable equipment open to society based on their function and application status, supervising the service quality according to the feedbacks from the customers and the professional operating agency. With equipments in hand, the laboratories implement $\mathrm{R} \& \mathrm{D}$ services according to customers demand.

To ensure an appropriate operational mechanism, Peking University R \& D Service Base introduced the revenue allocation rule to stimulate the activeness of related stakeholders to optimize the sharing of S \& $\mathrm{T}$ resources (see Table 1). Accordingly, from the total service revenue, MSAL takes $10 \%$ to cover its marketing 


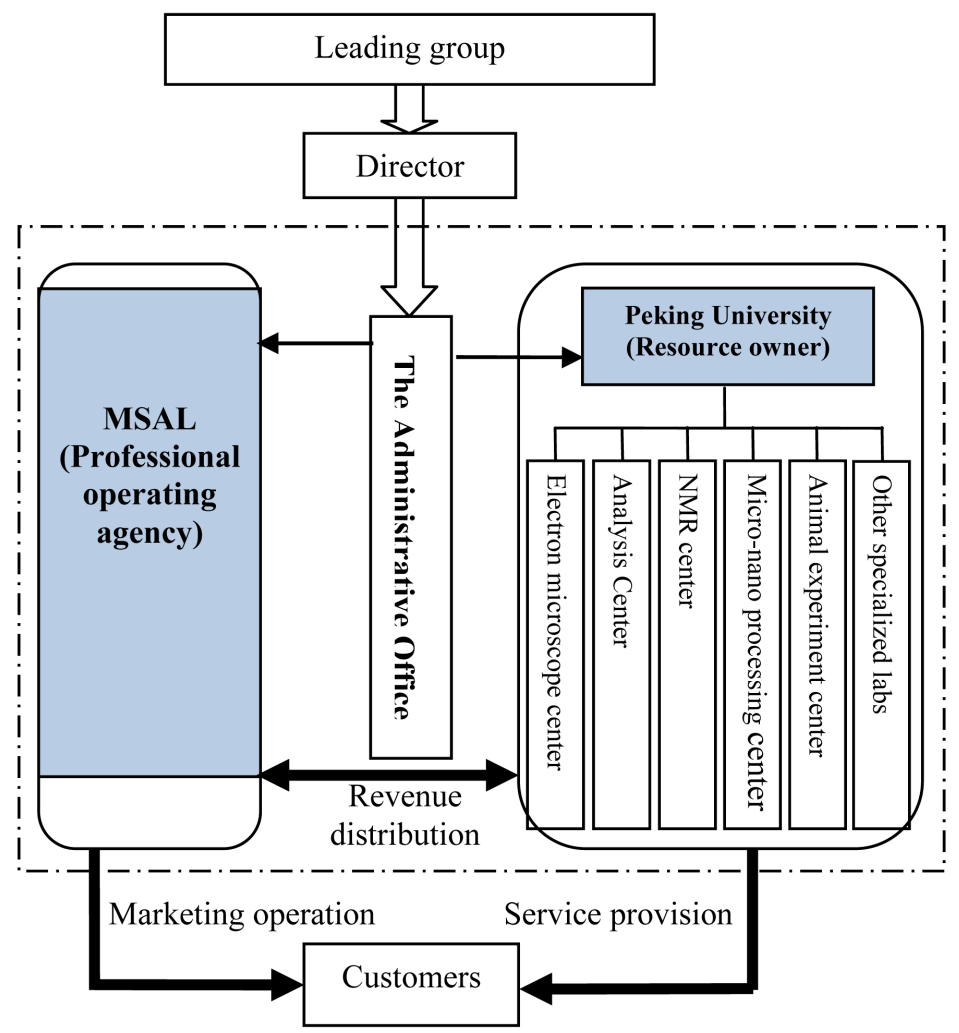

Figure 3. Organizational structure of Peking University R \& D service base.

Table 1. Revenue allocation of Peking R \& D service base.

\begin{tabular}{cc}
\hline & Allocation of revenue \\
\hline Management fee paid to university & $10 \%$ \\
Management fee paid to faculty & $10 \%$ \\
Intermediary fee paid to professional operating agency & $10 \%$ \\
Service fee paid to lab staffs & $15 \%-25 \%$ \\
Maintenance cost & $45 \%-55 \%$ \\
\hline
\end{tabular}

cost. The rest of revenue subtracting maintenance cost is allocated among university, faculty and lab staffs.

By September 2010 (less than one year after the R \& D service base was initiated), Peking University R \& D Service Base had provided technical service to nearly 400 enterprises, which were 258 more than the total amount of previous year, reaching 29,643,800 yuan service contract, at least reducing R \& D costs of 60 million yuan for the enterprises, generating economic benefits of 300 million yuan for the enterprises. A concrete case that Peking University R \& D Service Base helps to reduce cost of innovation in SEMs is given as follows:

HuaXi is a high-tech enterprise which engages in new drug development. In 2010 when it was developing a new drug, it needed an efficient, rapid and accurate physical analysis method to determinate the dimensional structure and composition of molecular compound to provide accurate three-dimensional molecular structure data for conducting computer-aided design. However, such analysis and testing work required precision crystal analysis equipment, which cost 3 - 4 million yuan, and needed support from specialists for equipment operating and data processing. It was an obstacle for HuaXi to purchase such equipment and employ specialists. Then HuaXi searched Peking University R \& D Service Base for help. After receiving the task, MSAL as the professional operating agency coordinated $\mathrm{R} \& \mathrm{D}$ resources distributed in related faculties to provide test equipment and expert personnel to complete such analysis. Eventually, HuaXi spent test fee for only 10,000 yuan. 


\section{Summary of CSTRP}

\subsection{Developing Close Interactions among University, Industry and Government}

According to triple helix theory, it is essential to form virtuous interaction among university, industry and government during the generation and application of new knowledge. CSTRP fits perfectly with the essence of the triple helix theory. It is the result of the joint efforts of university, industry and government, and it is also a platform for the three parties to interact with each other and to seek for mutual benefit. During the construction of CSTRP, Beijing Science and Technology Committee facilitated the integration and openness of S \& T resources (including equipments, personnel, and S \& T achievement) through institutional arrangements to better meet the technological innovation demand of SMEs.

Meanwhile, CSTRP can fundamentally alter the behaviors of individual helix and push forward the evolvement of the triple helix as a whole to an advanced level. First of all, the border of each helix is gradually fading out, which could be noticed from the changing roles of actors. For example, universities no longer engage only in education and scientific research; they are taking responsibility of social service as well. The specialized centers affiliated to the government take responsibility more than just managing the $S$ \& T programs; they start to explore S \& T demand and do market-oriented operations as well. Secondly, influence among helices is observed. The requirement to open S \& T resource from Beijing Science and Technology Committee changes the objectives of universities and pushes resource owners to develop intrinsic motivation of providing R \& D service. E.g., North China University of Technology (NCUT) has introduced a new policy that R \& D service is considered as workload and can be linked with the promotion of professional titles. This is a breakthrough to the university's traditional evaluation system which solely considers the output of theses and patents. Furthermore, new trilateral connections have been established among the three helices. From resource owners that join CSTRP, Beijing Science and Technology Committee selects several S \& T achievements, supports with fund and land, introduce social capital to together boost the commercialization of technology (e.g., establishing joint venture). Last but not least, the triple helix system generates a comprehensive effect in society: government transforms from project initiator and manager to resources supplier; SMEs transform from close innovation to open innovation; universities and research institutes begin to emphasize its duty of social service.

\subsection{Forming Long-Term Development Method in Multi-Level Governance}

As mentioned in the introduction sector, multi-level governance theory is of great reference to CSTRP. Accordingly, a long-term development method focusing on three levels was formed for the sustainable improvement of CSTRP.

Firstly, for field centers, major attention should be paid to better collect demand of enterprises. The field centers are sponsored by Beijing Science and Technology Committee to conduct survey on industrial demand and to construct new service modes together with resource owners.

Secondly, for R \& D service bases, the ability to achieve self-sustaining without government support should be enhanced. Note that professional operating agencies are exploiting new profit generating method by fully utilizing the opportunity to access S \& T resources in universities and research institutes. E.g., MSAL with testing service as main business begins to participate in technology transfer from university to industry.

Thirdly, for working stations, bridge function between the supply side and demand side should be further strengthened. Beijing Science and Technology Committee are developing more inter-government cooperation with governments of other cities, regions and countries to bring more customers for CSTRP.

\subsection{Forming Innovation Network Based on Operational Mechanism}

CSTRP forms an innovation network involving government, R \& D service bases, field centers, working stations, and SEMs (Figure 4) [8]. This innovation network is mainly connected through strong ties. For instance, the operational mechanism that between the professional operating agencies and the $S \& T$ resource owners, between the professional operating agencies and the specialized centers, between the specialized centers and regional governments etc are all built on the cooperation agreements, which states clearly the rights and responsibilities of related actors.

Besides, CSTRP successfully fills the "structural hole" in the innovation network. E.g., professional operating agencies are introduced to connect enterprises and resource owners (universities and research institutes); regional 


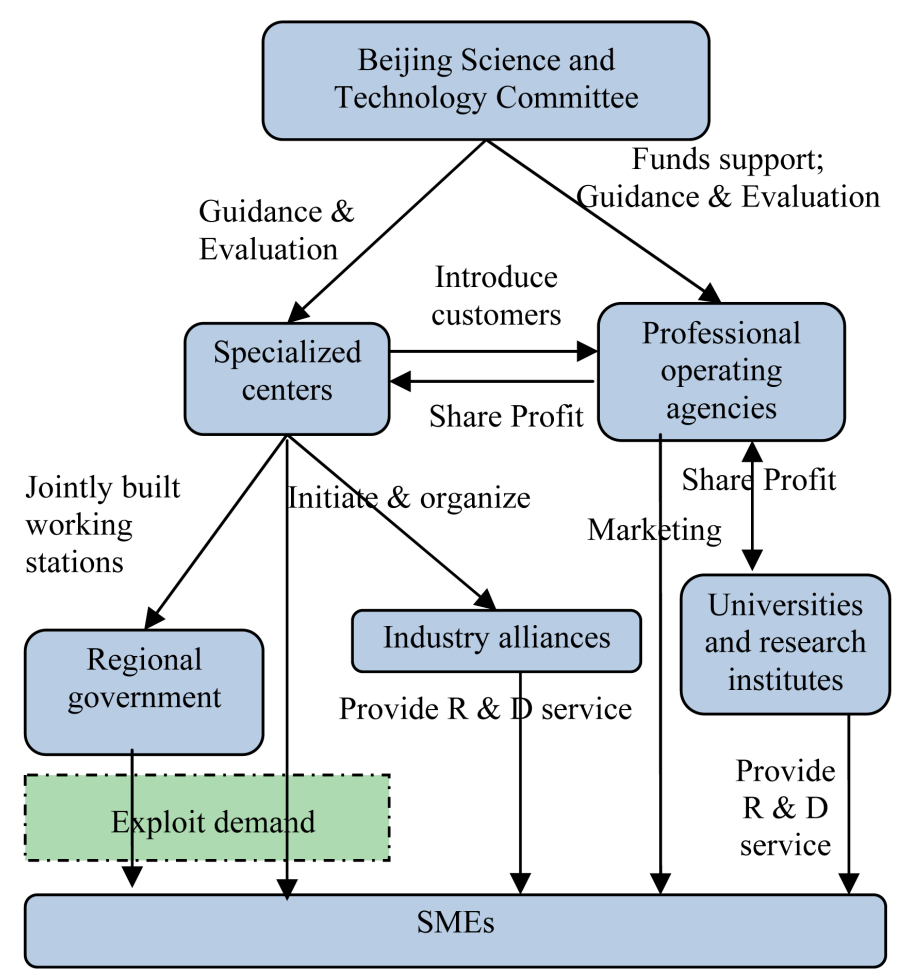

Figure 4. Innovation network of CSTRP based on operating mechanism.

governments and industrial alliances that used to have no links with R \& D service bases establish connections via specialized centers affiliated to Beijing Science and Technology Committee.

\section{Conclusion and Discussion}

\subsection{Conclusion}

To promote sharing of science and technology resource in universities, research institutes and enterprises in recent, Beijing Municipal Science and Technology Commission explored Beijing Mode with their practice. This paper overviews the distribution of science and technology resource in Beijing and introduces the system reformation history of CSTRP as background information. It analyzes the characteristics and highlights of CSTRP after the reform and discusses the underlying theories including triple helix theory, multi-level governance theory and innovation network theory. Accordingly, the new practice of CSTRP introduces market-oriented professional operating agencies to bridge resources owners and resource users, designs a win-win mechanism to benefit different actors, and transforms the policy focus. It has developed close interactions among university, industry and government, established long-term development method in multi-level governance and constructed innovation network based on operational mechanism.

\subsection{Suggestion on CSTRP's Future Development}

Technological innovation in enterprises is a process of integrating inside and outside resources, including information, personnel, technology, patent and equipments, etc. CSTRP is developed by government and innovators to provide SMEs with resources mentioned above as well as R \& D services based on the resources. In order to achieve sustainable long-term development, CSTRP should seek for continuous improvement in service delivery, organizational management and mechanism design, etc. The following suggestions could be made for the future construction of CSTRP:

First, enhance the profitability of CSTRP. For those R \& D service bases which rely on government financial support, Beijing Science and Technology Committee should gradually change the funding method from annual fixed input to subsidies after service delivery. Transform the professional operating agencies from information 
intermediaries that only bridge supply side and demand side to professional service organizations that can add value to R \& D service. Transform CSTRP from a system combined by administrative policies to a system based on benefit-sharing mechanism. Keep on government funding on specialized centers for a certain period since they can't cover the operating cost at present.

Second, extend the boundaries of CSTRP through building official or unofficial connections with other regions to integrate more $S \& \mathrm{~T}$ resource as well as to deliver $\mathrm{R} \& \mathrm{D}$ services to larger geographic areas.

Third, shape the CSTRP brand image by carrying out standardized service procedure and uniform management. Besides, maintaining the distinct characteristics of different R \& D service bases and their personalized services to create competitions inside CSTRP.

Fourth, use IT to enhance resource information sharing and to improve service efficiency. It is feasible to construct four major databases, i.e., the equipment database, the technology achievement database, the expert database and the service demand database.

Fifth, combine CSTRP with the start-up programs. Nowadays in China, more and more college graduates are enthusiastic about starting up their own business but facing shortage of resources. CSTRP can provide these entrepreneurs with S \& T resources and related R \& D services to create not only large economic value but also great social value.

\subsection{Limitation of This Paper}

This paper serves for the purpose of introducing the practice of Capital Science and Technology Resource Platform (CSTRP) in Beijing and the underlying theories it's based on. We also raise several suggestions on the long-term development of CSTRP.

Due to our knowledge limitations, interpretations on CSTRP might not be exhaustive. Although theoretical analysis could be useful for a better understanding of the construction of CSTRP, there might be other suitable theories besides triple helix theory, multi-level governance theory and innovation network theory.

\section{Acknowledgements}

The authors want to thank Beijing Science and Technology Committee for providing financial support for the research (project number: Z101109000510022).

\section{Funding}

This research was supported by Guangdong province's soft science project "Study on Principles and Methods of Guangdong Roadmap for Developing Industry Leading Scientists” (2015A070704036).

\section{References}

[1] Beijing Municipal Bureau of Statistics, NBS Survey Office in Beijing (2015) Beijing Statistical Year Book 2015. http://www.bjstats.gov.cn/nj/main/2015-tjnj/indexeh.htm

[2] Beijing Technology Market Management Office (2014) Beijing Technology Market Analysis Report. http://www.cbtm.gov.cn/bjissc/scjc_show_ids503monitorTypes1.html

[3] Etzkowitz, H. and Leydesdorff, L. (2000) The Dynamics of Innovation: From National Systems and "Mode 2" to a Triple Helix of University-Industry-Government Relations. Research Policy, 29, 109-123. http://dx.doi.org/10.1016/S0048-7333(99)00055-4

[4] Li, P.F. (2014) Effectiveness Analysis and Policy Recommendations of the Triple Helix of University-Industry-Government in China. Science of Science and Management of S. \& T., 35, 3-9. (In Chinese)

[5] Hooghe, L. and Marks, G. (2001) Multi-Level Governance and European Integration. Rowman \& Littlefield Publishers, Oxford.

[6] Bache, I. and Flinders, M., Eds. (2004) Multi-Level Governance. Oxford University Press, Oxford. http://dx.doi.org/10.1093/0199259259.001.0001

[7] Kaiser, R. and Prange, H. (2004) Managing Diversity in a System of Multi-level Governance: The Open Method of Co-Ordination in Innovation Policy. Journal of European Public Policy, 11, 249-266. http://dx.doi.org/10.1080/1350176042000194421

[8] Freeman, C. (1991) Networks of Innovators: A Synthesis of Research Issues. Research Policy, 20, 499-514. 
http://dx.doi.org/10.1016/0048-7333(91)90072-X

[9] Fagerberg, J., Mowery, D. and Nelson, R., Eds. (2004) The Oxford Handbook of Innovation. Oxford University Press, Oxford.

[10] Baker, W.E., Grinstein, A. and Harmancioglu, N. (2016) Whose Innovation Performance Benefits More from External Networks: Entrepreneurial or Conservative Firms? Journal of Product Management, 33, 104-120. http://dx.doi.org/10.1111/jpim.12263

[11] Li, J.Z. and Deng, Q.W. (2011) Beijing Mode to Promote Openness and Sharing of S \& T Resources. China Science \& Technology Resources Review, 43, 1-10. (In Chinese)

[12] Li, J.Z., Deng, Q.W. and Chu, W.B. (2012) Practical Exploration and Theoretical Distillation of "Beijing Mode”. China Science \& Technology Resources Review, 44, 17-23. (In Chinese)

[13] Li, J.Z., Deng, Q.W. and Sorensen, O. (2011) Building National Innovation Platform in China: Theoretical Exploration and Empirical Study. Journal of Science and Technology Policy Management, 2, 58-78. http://dx.doi.org/10.1108/17585521111107898 